\title{
ANTI-VENEREAL MEASURES IN DENMARK AND SWEDEN*
}

\author{
By L. W. HARRISON, D.S.O., M.B., Ch.B., F.R.C.P. (Ed.).
}

As most of the substance of this paper is derived from the report of an official mission to certain Scandinavian countries to study their anti-venereal measures, it seems proper that I should say something about the events which led to our being sent there.

In 1936 there was published in America the report of a mission from New York to Denmark, Norway, Sweden and Great Britain to study the anti-venereal measures in these countries. In the New York Report this country did not make such a good showing as did, at any rate, Sweden and Denmark, and the comparison resulted in a revival in certain quarters here of a demand for the institution of compulsory treatment of venereal diseases in Great Britain.

The British Social Hygiene Council, in whose house this suggestion was raised, were by no means unanimously of the opinion that compulsory treatment was the prime factor in the Scandinavian results and thought that the conditions there ought to be studied by an independent body; accordingly, they asked the Minister of Health to finance a mission to be organised by themselves for the purpose. The Minister did not accede, but in response to a request in Parliament joined with the Secretary for Scotland in the despatch of an official mission to Denmark, Norway, Sweden and Holland for the same purpose. Holland was added because a very low incidence of syphilis had been reported in that country in spite of the absence of any compulsion, and it was felt that observations in Holland might act as a control on those in the Scandinavian countries.

Our mission, consisting of Mrs. Rorke, Dr. Ferguson, of the Department of Health for Scotland, Mr. Dudley Ward, of the Ministry of Health, and myself, spent three

* Based on an address to the Medical Society for the Study of Venereal Diseases, November 24 th, $193^{8}$. 


\section{BRITISH JOURNAL OF VENEREAL DISEASES}

weeks in July, I937 studying the conditions on the spot, and later some of us toiled with the Report, which was eventually published in January, I938. Those who have studied this report may find it much easier to follow the present paper than will those who have not done so. It seems justifiable to say here that we took great pains to get our facts correct and did not send in the Report until we had obtained an assurance from responsible officials in each of the countries reported upon that the section which related to it gave an accurate account of the position and without omission of any important detail.

Our aim was to study in each country the laws relating to venereal diseases, how they were being worked, the reaction of the people to them, the incidence of venereal diseases and the relative importance of various factors to the incidence.

In our pursuit of this knowledge we interviewed medical officers of health administrations, directors of V.D. clinics, medical officers of the State Serum Institute in Copenhagen, lay administrators and police officials ; also in Sweden we made an attempt to discover what the man in the street thought of the anti-venereal laws. Statistical data were derived directly from official sources whenever they were available there.

For the purpose of this paper it has proved difficult to choose a method of presenting the subject which will give a reasonably clear idea of it in the relatively short space that is available but it seems best to confine it to conditions in Denmark and Sweden because in these countries there are ad hoc anti-venereal laws. I am starting with Sweden because admittedly the laws in Sweden are more complete and detailed than those in the other countries, and the Swedish statistics seem to be the least open to question. After sketching the conditions in the two countries, I propose to discuss the bearing of the various factors on the results.

The history of the events leading up to the present Swedish laws is a long one ; it has been described reasonably fully in the official paper, but there is little space for it here. The principle of stopping the spread of venereal diseases by free treatment of the infected was put into practice first in I8I7, about thirty years after Denmark had started it. The principal law under which the 
present anti-venereal measures operate in Sweden is the Act of June 2oth, I9I8 relating to measures for the Prevention of the Spread of Venereal Diseases. It came into force on January Ist, I9I9, and was the culmination of a long-fought campaign started in 1880 for abolition of the so-called Regulation of Prostitution. The Act is based on a study of the subject of venereal disease in all its aspects by a commission which presented a report of $\mathrm{I}, 600$ printed pages in the year I9Io. The recommendations of this commission were translated into the Act of I9I8 by a sub-committee of two in I9I6-I7, the subcommittee consisting of Dr. Marcus of the St. Göran's (Venereal) Hospital, Stockholm, and Mr. Ribbing, a legal member of the Royal Medical Board which regulates the medical services in Sweden.

The Swedish Act of I9I8 defines venereal diseases as syphilis, gonorrhœa and soft chancre in their infectious stages. Persons suffering from venereal diseases so defined are bound by law to undergo treatment until considered to be free from infection. At the first consultation the doctor, whether private or public, must give the patient Form VI. on which are set out information on the nature of the venereal diseases and the laws on the subject. The patient has to sign on Form VII. a receipt for Form VI. so that he cannot afterwards plead ignorance if he is found to have broken the law.

Treatment is provided everywhere free of cost to the patient. In towns of 20,000 or more inhabitants the treatment must be provided in policlinics, of which there are twenty-two in the country. In smaller towns it is given by municipal or State-employed district medical officers, who receive for this service fees over and above their salaries; the fees are according to the scale laid down by the State and set out in the official report. Owing to the fact that the management of the diseases is mostly by medical officials the whole is very closely under the control of the central government ; it may be worth noting here that considerably more than half the medical practitioners in Sweden (in I934, I,63I out of 2,732) are employed either whole- or part-time by the State or by local authorities. Also the treatment which is actually given is probably more uniform than in any other country owing to the fact that practically all the medical officers have studied venereal diseases at the same 
school, the St. Göran's Hospital, Stockholm. Another point of importance is that the medical curriculum lasts at least seven and a half years after the preliminary scientific subjects have been passed and includes dermatosyphilology amongst other special subjects in which examiners have to be satisfied. It follows that even in the smallest hamlets in Sweden the treatment of venereal diseases is in the hands of medical officers who have received a special training in the subject.

The treatment of early syphilis is said to extend to three years. It starts with two courses of an arsphenamine preparation concurrently with bismuth and continues with bismuth. We were told repeatedly that any patient who failed to attend for the three years would be reported. Women who have undergone the full treatment and later become pregnant are also treated free, though not compelled to attend.

The treatment of gonorrhœa in the male is on very simple lines. For the most part it consists of selfadministered urethral injections of an organic preparation of silver. Instruments seem never to be used. Cure is determined by a series of negative smears. Each smear is taken by the M.O. passing a narrow spoon, rather like an aural scoop, into the urethra. The female nurse, who is present all the time, takes the scoop and makes a smear of the secretion which it has picked up, stains the smear with a simple dye (not Gram) and hands it to the M.O., who examines it on the spot ; the whole business from taking of specimen to dismissal of the patient occupies only a few minutes. So far as we could discover, neither cultures nor the complement fixation test are employed. Mrs. Rorke's report will doubtless furnish details of treatment of gonorrhœa in females.

If a patient fails to attend, he (by he I shall mean also she) receives a notice on Form VIII. calling on him either to reattend or to furnish proof that he is under the care of another doctor. If the patient fails to comply, he is reported to the Inspector of Health on Form IX., and the Inspector then sends the patient Form XVIII. reuqesting him to resume treatment and warning him of the consequences of failing to comply with the order. If this fails, the matter is reported to the Department of Health, who take steps, with police help if necessary, to remove the patient to hospital. The police are not 


\section{ANTI-VENEREAL MEASURES IN DENMARK}

informed of the nature of the patient's infection, and in visits to patients' homes for the purpose of the Act the officers wear plain clothes.

In certain circumstances, e.g., when a patient is known to be recalcitrant, the warning on Form XVIII. is omitted, and the Inspector of Health takes immediate steps to secure the patient's removal to hospital.

Another incentive to a patient to attend regularly to the end is the Penal Code under which a person who, knowing or suspecting that he is suffering from a venereal disease in an infectious stage, subjects others to the risk of infection, through sexual intercourse, or through unchastity not leading to sexual intercourse, or otherwise by negligence is liable to imprisonment or a fine : if venereal disease results from the act, the imprisonment may be up to two years with hard labour.

How successful are the various measures in securing continuation of the patients' attendance? In the ten years, I926-35, the number of notified cases in Sweden was 137,563 , and of these II,378, or approximately 9 per cent., were reported for discontinuance of attendance. Approximately 25 per cent. of the defaulters could not be traced and 8, I06 resumed attendance, three-quarters of them as a result of action by the Department of Health or the police.

The law would permit of a patient being treated by force if necessary, but as a matter of fact this has never been done. If a patient brought an action for damages on the grounds of having suffered in health through administration of the treatment the Court would normally be guided in its decision by the opinion of a medical specialist to whom the case had been referred. The opinion would be stated on paper, and the specialist would not normally have to stand the fire of cross-examination by the complainant's counsel.

Under the Penal Code a person suffering from a venereal disease in an infectious stage may not marry without the permission of the King, and before marriage both parties must furnish written declarations of freedom from venereal disease. If a doctor learns that a patient he is treating for venereal disease contemplates marriage, he is required by law to inform the Inspector of Health who sends the patient a Form requiring him to be examined. 


\section{Ascertainment OF $^{*}$ Sources OF INFECTION}

The law requires the doctor at the time the diagnosis is made to try to ascertain the source of the patient's infection and there is a space on the notification form (Form I.) for insertion of the name and address of the infecting party. If the Inspector thinks the information is reasonably reliable, he sends the accused person a notice requiring him to undergo examination either by a medical officer appointed by the Inspector or by his own doctor; in the latter case a certificate of the result of the examination is furnished on Form XIII.

Failure on the part of the person accused of having caused an infection to undergo examination could lead to removal to hospital and forcible examination.

In this the reader may see an opportunity to bring under treatment any person suspected of living unchastely and may perhaps imagine opportunities for blackmail, but actually the Swedish authorities appear to have had little trouble from this source. Another point which will no doubt occur to the reader is that the patient when giving the information is in a position to know that the person accused of being the source of the infection could, if proved to be suffering from V.D., be prosecuted for having by sexual intercourse or by unchastity not leading to sexual intercourse, or by neglect in some other way caused another person to be infected. Actually we were told that this is seldom done in Sweden, but what seems to matter here is not what is done but what the patient thinks is likely to happen, and there may perhaps be here an incentive to the patient, acting under a motive of gallantry, to give misleading information. It was my experience in the War of I9I4-I8, and I have seen it reported more than once in French medicomilitary literature, that a soldier would commonly give information leading the Provost-Marshal's staff miles away from the particular nest where he caught his infection.

The information which we were able to obtain did not give us the impression that ascertainment of sources of infection under the Swedish laws was very successful. Of the 137,563 notifications of V.D. from 1926 to 1935 the number in which information as to infection was given was 17,480 , or 12.7 per cent., and of the persons reported, 


\section{ANTI-VENEREAL MEASURES IN DENMARK}

less than three-fifths were brought under treatment, while over 7,000 were either found to be free from infection or were not traced.

According to an article published in I93I by Dr. Bladini, Assistant Medical Officer of Health, Gothenburg, the search for sources of infection is much more successful in rural areas than in towns. From the table in Bladini's article one infers that in the rural areas infecting persons were discovered and brought under treatment in approximately I 5 per cent. of the notified cases, while in the towns the corresponding percentage was less than 5. Bladini's conclusions seem to be supported by some figures which we obtained in Stockholm. Here in I93I in 4,964 notifications only 354 contained usable particulars of alleged sources of infection, and of these only 136, or 2.7 per cent. of all the notifications, led to discovery and treatment of infected persons. In I934 the corresponding percentage was $5 \cdot 4$.

It seems possible that doctors are not entirely blameless for the relatively small numbers of sources of infections that are reported in the large towns. At any rate a few months ago Dr. Rietz, Medical Officer of Health, Stockholm, told me orally that a little time ago he called a conference of practitioners in Stockholm to discuss this matter. He reminded them of their duties in respect of tracing sources of infection and stressed the importance of it. The result was that in the following year the percentage of notifications in Stockholm bearing information as to source of infection, increased to 25 .

The results of the Swedish anti-venereal measures can be summed up shortly as a brilliant success in the case of syphilis, but relatively indifferent in gonorrhœa.

In I9I9 the incidence of acquired syphilis in Sweden was $10 \cdot 2$ per 10,000 of the population, the following year it was $5 \cdot 2$, and by 1925 it had dropped to I.2. Between I925 and $\mathrm{I} 933$ it ranged between $\mathrm{I} \cdot 3$ and $2 \cdot 0$, and after I933 it began to fall again, reaching 0.67 in 1935 . According to figures given to me a few months ago by Dr. Rietz, it fell in I936 to less than $0 \cdot 6$, and the preliminary figures for 1937 showed a still further fall.

In Stockholm, although the rates were higher than those for the whole country, they showed equally remarkable falls. In I9I9 the rate was $44^{\circ} \mathrm{O}$, and in I 920 it was 25. I. By I925 it had fallen to $4 \cdot 6$, but after this year the 
rate rose again, reaching $12 \cdot 2$ in 1927 , after which it dropped pretty steadily to $\mathrm{I} \cdot 8$ in $\mathrm{I} 935$, and in 1936 it was even lower, at $\mathrm{I} \cdot 2$.

In the other two large towns of Sweden the incidence trends have been roughly similar to those in Stockholm.

In congenital syphilis the decline in incidence has been equally remarkable. In I920 the notified cases were I65, and in 1935 they were only I9. In Stockholm the figures were 34 in 1920 and 5 in 1935 .

In gonorrhoea the rate in I935 was half that in I9I9, viz., 17.9 per 10,000. In Stockholm the rate in 1935 was $65^{\circ} 0$, or approximately one-third of that in IgIg. In Gothenburg, from I92I to I 935 there was a fall of about one-third, and in Malmö the fall was about one half. One might be tempted to think that these were quite encouraging declines, but a rate of 17.9 per I0,000 was about double that of cases of gonorrhoea dealt with for the first time in treatment centres in England and Wales in I935. It is not suggested that cases dealt with for the first time in treatment centres were the majority of the cases that came under medical care in England and Wales, but it is right to say here that the density of population of Sweden is approximately one-eighteenth that of England and Wales. and a rate of $17 \cdot 9$ per 10,000 in such a sparsely populated country as Sweden does not suggest a brilliant success of the anti-venereal measures so far as gonorrhoa is concerned.

We found no evidence that the Swedish laws had resulted in any concealment or had proved particularly difficult to administer. If the statistics relating to reports for failure to attend are correct, there is much less defaulting in Sweden than here, but we had no opportunity of verifying that defaulters are always reported.

In any case, whatever the cause there is no doubt that Sweden has had remarkable success in reducing the incidence of syphilis, and now with the help of the new chemo-therapy there is good reason for hope that there may soon be a similar fall in the incidence of gonorrhœa.

\section{DENMARK}

The laws in Denmark are not so precise as in Sweden, but their effect is broadly similar. Free treatment for all regardless of status was first established in Aarhus in 
I788, and became universal throughout the country in I790. In I874 a new law made treatment also obligatory and made it possible in certain cases to remove infected persons to hospital. It provided also for police regulation of prostitutes and for their examination. This law was replaced in 1906 by The Law to Combat Public Immorality and Venereal Contagion, which is still in force.

Under this law regulation of prostitution was abolished but repressive measures were stiffened up, as were also the measures to insure continuation of treatment and prevention of infection of marital partners, paramours, infants, wet nurses and others.

The law requires the doctor whom the patient first consults to make him aware of the nature of his disease and of the penalties which would result from his failure to continue treatment until pronounced free from infection. All these instructions are contained in a special form (Form 54) given to the patient, and as neglect on the part of the doctor to give them is punishable by a fine of $200 \mathrm{Kr}$. he often obtains from the patient a receipt for them. The receipt also deprives the patient of any plea of ignorance if he is accused of exposing others to the risk of infection, an offence which is punishable by imprisonment up to four years.

Women suspected of living a life of prostitution can be called on to produce evidence that they are gaining a livelihood by lawful means (prostitution being unlawful). If the reply is unsatisfactory, the woman may be ordered to seek legitimate employment and to report to the police at intervals. Also any person who has been imprisoned for neglecting to seek legitimate employment may, within a period of five years, be required to report to the police as to her means of livelihood.

It is forbidden to put out to nurse an infant suffering from an infectious venereal disease without informing the proposed foster-mother, and no woman who knows or believes herself to be syphilitic may suckle another woman's child under a penalty of imprisonment for three years.

Unlike the case in Sweden, the doctor is not required to attempt to trace the source of infection, and this is thought by some critics to be a weak point in the Danish arrangements; in fact, in Copenhagen lately there has 
been an unofficial attempt to introduce a system of following up such sources. There are, however, ways and means of securing the examination and treatment of persons who are believed to have infected others. Thus, as mentioned, it is an offence to infect another person, and anyone accused of so doing can be subjected to examination. Also, persons known to be leading a life of prostitution, or suspected of such, or charged with solicitation, can be subjected to examination.

In accordance with a law of 1922 persons about to marry must either sign a declaration of freedom from venereal disease or produce a medical certificate to the same effect. A marriage can be annulled if at the time it was contracted either of the parties was suffering from venereal disease in an infectious stage.

A patient can obtain treatment privately, and in this case the law as to warning the patient and as to continuance of treatment applies as if the treatment were free. By far the larger proportion of patients with V.D. avail themselves of the facilities for free treatment, which is given in policlinics of hospitals and in dispensaries in Copenhagen, in a policlinic in Aarhus, and elsewhere by the district health officers, who are paid extra at an official rate per consultation. In the remoter rural areas the treatment is given by general practitioners. The training of doctors in Denmark appears to be such as to ensure that the district health officers and general practitioners have a good working knowledge of V.D. This will be clear from the following extract from a recently published booklet on "The Combating of Venereal Diseases in Denmark," published by The National Health Service in collaboration with Dr. Kissmeyer, Physicianin-Chief, Commune Hospital, Copenhagen.

"The training of medical students in dermatology and venerology in Denmark began with the nomination of Sophus Engelsted, the senior chief of the dermato-venerological department of the Kommunehospital (Municipal Hospital) in Copenhagen, as a lecturer at the University in I869. In I9II the Chair was moved to the Rigshospital (State Hospital) and in I9I6 it was converted into a professorship. During the undergraduate training, lasting about seven years, students have to attend the obligatory lectures and pass an examination. For one month during their years of study they generally assist as " practicand " at the daily work of one of the dermato-venerological departments of Copenhagen. From January, I939 there will be two professors in the discipline 


\section{ANTI-VENEREAL MEASURES IN DENMARK}

at the University of Copenhagen, an ordinary and an extraordinary " clinical " professor. At the newly-founded University of Aarhus no professorship in Dermatology has yet been erected. Physicians who wish to be Public Health Officers have to pass a special course in venerology."

"In order to acquire the right to describe himself as a specialist in dermato-venerology a medical practitioner must, according to the Act of March I4th, I934 ("The Medical Act") receive authorization from the National Health Service. To obtain this authorization he must have had recognised house-surgeon service of one year (in medicine and surgery) and three years training as first assistant in a dermatological department with a policlinic."

The treatment of syphilis seems to be almost as uniform as in Sweden, and probably most practitioners follow the system of the State Hospital in Copenhagen, where they were taught syphilology. Sero-negative primary cases receive two courses of " $9 \mathrm{I} 4$ " and bismuth, each totalling 6 arsenical and 12 bismuth, and sero-positive primary and secondary cases four such courses.

In gonorrhœa of the male the treatment and tests of cure are on rather similar lines to those in Sweden, but some urethroscopy and instrumentation are practised in the hospital clinics in Copenhagen and the gonococcal complement fixation test is used to a certain extent.

All serum tests are carried out in the State Serum Institute. The fee for a routine test, i.e., Wassermann and Kahn, when the patient is under the free-treatment scheme, is I Kr. If an extended examination is required or considered necessary, in addition to the Wassermann and diagnostic Kahn, a Müller, a Meinicke and a Kahn presumptive test are carried out, and the fee for all this is $2 \mathrm{Kr}$; the corresponding fees for private patients are 5 and $6 \mathrm{Kr}$.

The procedure in Copenhagen, when a patient fails to attend for treatment, is first that the M.O. responsible for his treatment sends him Form 57, requesting him to reattend or give evidence of being under treatment by another physician. If this request is ignored, the patient is reported to the M.O.H. who sends the report to the M.O. of the V.D. dispensary nearest the patient's residence. This M.O. then sends Form 56 to the patient requiring him to report to him at the Dispensary. If he still fails to attend he is reported to the Morals Police (a special department) on Form 2.

So far as we could ascertain, the arrangements work 


\section{BRITISH JOURNAL OF VENEREAL DISEASES}

smoothly; they do not seem to have caused any undue amount of concealment and patients do not often seem to give false names and addresses. In 1936, out of I,044 persons who were reported for discontinuance of treatment in Copenhagen, only 44 were untraced; the remainder were accounted for in one way or another, and 826 were restored to treatment. In the same year the number of notifications in Copenhagen was 5,529, so that the law seems to have to be put into operation in about one-fifth of the notified cases.

In I933, Kissmeyer reported that in I93I, of 5,295 notified cases, 80 per cent. completed treatment without the intervention of the health authorities or the police, and of the remainder, all but 9I were restored to treatment. On the face of it the system seems to be very successful in securing completion of treatment of a very high proportion of the cases.

One Danish worker has stated that the law under which any person who knows or suspects he is suffering from a venereal disease and exposes others to the risk of catching his infection can be imprisoned or fined is a potent factor in holding patients to treatment, but actually the law seems relatively seldom to be invoked in such cases. At any rate, in Copenhagen in I936 only 87 such accusations were made, 43 against men and 44 against women, and proceedings were abandoned in 63 of them. This was in spite of the fact that the Court requires only a certificate by a doctor that the accused person is suffering from venereal disease. If the accused person is a woman, the Court is satisfied with evidence that she has lived as a prostitute.

In Copenhagen, also, in I936 there were 379 medical examinations of persons accused of infecting others, or of prostitution, or of procuration, and no less than 368 were women, but only 64 examinations of these women appear to have resulted in a diagnosis of venereal disease. In the cases of the II men 5 were found to be suffering from venereal disease. A person can be forced if necessary to undergo examination, but in all these cases consent was given. We were told there had been very little trouble from blackmail.

Certain institutions have been established to help patients, chiefly women, with venereal diseases when they leave hospital. The following information respect- 
ing these is derived from "The Combating of Venereal Diseases in Denmark" already mentioned.

The Danish Women's Welfare (founded in I922) gives lodging to needy women and helps them to get work. At their " home" in Copenhagen a woman doctor treats those with V.D. The "Magdalene Home" has a home in Copenhagen for eight young girls who have gone astray. Here they can rest for some days until they can get a situation or are transferred to the principal home (for 55 girls) where they stay longer, generally three years, and are taught.

The "Society for the Moral Rehabilitation of Young Women " works with the Morality Police and has a hostel for girls and women who have been in conflict with the law.

Also, as in Sweden, there are Welander homes for syphilitic children. On these and the prevention of congenital syphilis the following extract from the booklet already mentioned is of interest.

"The idea of treating the congenitally syphilitic children in special asylums and keeping them there as long as may be necessary for their treatment-often also for social reasons-was that of the Swedish dermatologist, Edvard Welander, who in December, I900 opened the first home for syphilitic children in Stockholm. In Denmark a similar asylum was established in 1905, and in I9I6 a new and quite modern "Welander Home " was opened at Bispebjerg, a suburb of Copenhagen, containing 52 beds. Up to December 3Ist, I937, five hundred children had been treated there, many of them knowing no other home and some of them remaining there until their sixteenth year. The children frequent a municipal school in the neighbourhood of the asylum."

"In I9I 8 another home was opened at Elsinore for thirty boys, but closed its doors in 1937, congenital syphilis being in so marked a decrease that the home seemed superfluous. As the last the "Ehlers Home" in Slesvig, for thirty girls and infants, was founded in 1925. On the 4th August, I924, a department for observation of children born of syphilitic mothers, but not themselves showing any clinical sign of syphilis, was established in the Welander Home at Bispebjerg. The children are generally kept under observation there from four to six months."

"The upkeep of the Welander asylums is defrayed partly by private foundations, but a ministerial order of October 2nd, I9I7, confers similar rights on the asylums as hospital departments treating venereal diseases; this means that the municipalities and the State pay the charge for sojourn and treatment. At Bispebjerg a dermatologist and a pediatrist attend to the children; the children at the Ehlers Home are treated by a practitioner in a neighbouring town." 


\section{BRITISH JOURNAL OF VENEREAL DISEASES}

"A very important measure to avoid congenital syphilis is prenatal treatment. Pregnant women who have had syphilis, even if the infection dates back many years, will always be given free treatment, if they attend a policlinic. It may safely be said that pre-natal treatment, even in old infections, is the rule in Denmark now and it is undoubtedly the principal cause of the great decrease of congenital syphilis in late years."

The incidence of venereal diseases in Denmark is not easy to determine because the official figures contain an unknown number of duplicates and of cases whose infections are not recent. Since the beginning of 1938 practitioners have been instructed to report only recent cases.

It is generally admitted that the most reliable source of information on the incidence of syphilis in Denmark is the records of the State Serum Institute. Here, under a system of filing instituted by Dr. Jersild in I920, it is possible to trace the syphilitic serological history of any patient whose blood has ever been tested in Denmark, provided that the sex, intitials, and birthday particulars have been entered correctly on the form accompanying every specimen of his blood.

As a result of an analysis by Dr. P. Krag, head of the department for syphilitic serum tests, of records sent with specimens of blood in the year ending March 3Ist, I936, one might reasonably suspect that by no means all cases are notified even when they first come under medical care. Dr. Krag found that I,7I3 of the records he analysed related to cases of syphilis whose serum had not previously been tested in the Institute between I920 and I935. I think one can safely say this means that most of those I,7I3 cases had not previously been treated for syphilis, because Danish doctors make very free use of serum tests, and one would have thought therefore that a substantial proportion of them would have been notified in accordance with the law. Actually the number of notifications of syphilis cases in the twelve months in question was less than half of the I,7I3.

As we could not rely on the notifications for an accurate figure of the incidence of fresh syphilis which we could use for comparison with rates in other countries, we were driven to making an estimate chiefly from the details of Dr. Krag's figures and from a calculation made by Dr. Svend Lomholt a few years previously, also as a result 


\section{ANTI-VENEREAL MEASURES IN DENMARK}

of a study of the figures at the State Serum Institute. Dr. Lomholt's estimate was that in 1933 the number of fresh infections in Denmark was 70o. To be on the fair side we made.an estimate of a minimum of 600 cases in the year I935. This is certainly an enormous reduction since I9I9, when Lomholt estimated the fresh infections to have been 4,500 , but the figure of 600 represents a rate per 10,000 of the population, which is not much less than what we calculate to have been the rate of fresh infections in England and Wales in 1936, viz., less than $\mathrm{I} \cdot 7$ per Io,000.

In the case of gonorrhœa we have only the official figures, which are probably more accurately representative of the trend of fresh infections than are the figures relating to syphilis. The figures in 1936 represented no decline in the incidence of gonorrhœa in Denmark as a whole as compared with the rate in the year 1906, but Copenhagen showed a decline of about 37 per cent., though in the years between 1906 and 1935 the rates had been considerably higher.

\section{Summary of the Results in Sweden and Denmark and Opinion as to the Responsible Factors.}

Our published report made clear our view that the anti-venereal laws in Denmark and Sweden work smoothly, are not abused and have apparently not caused any concealment of disease.

There can be no doubt also that they have resulted in a very great reduction in the incidence of syphilis in both countries and especially so in Sweden.

As regards gonorrhœea, although the rates in 1936 were certainly much less than in I9I9, it must be admitted that they were still very high in relation to the theoretical expectation under laws which require continuance of attendance until cure and provide for punishment for transmission of venereal disease ; although the cause may be attributable to defects in tests of cure, one would hardly advance as evidence of the effectiveness of the antivenereal measures in Denmark and Sweden the present incidence of gonorrhœe in those countries.

The question arises, if the laws on compulsory treatment, punishment for transmission of infection and prevention of marriage of infected persons have been a 


\section{BRITISH JOURNAL OF VENEREAL DISEASES}

dominant factor in reducing the incidence of syphilis. My colleagues and I concluded that they have not, except in so far as they cause to be brought emphatically to the notice of the infected person the importance of perseverance in treatment.

In either of these countries one would expect a big reduction in the incidence of syphilis if one explained to the people the nature of syphilis and the necessity of treatment because the circumstances are so favourable. In each case one is dealing with a relatively sparsely populated country, with facilities for diagnosis and treatment by a trained man in every corner of it and a reasonable people always willing to act on their doctors' advice. In such circumstances it seems to me that it would be extraordinary if methods of persuasion did not effect a substantial reduction in the incidence of syphilis, because I believe that if one could give every patient with early syphilis three months steady treatment, the percentage which would later become infectious would be so small as to have a negligible effect on the spread of the disease.

I think that this must be the explanation of the fact that in England and Wales according to my calculations, and I have spared no pains to arrive at the truth in this matter, the incidence of new syphilitic infections is very little if any greater than that which we have calculated for Denmark, and this is in spite of the fact that the density of our population and our free communication with highly infected countries would excuse a far higher rate.

It may, of course, be argued that we may have done fairly well in this country with our anti-venereal measures on voluntary lines, but we should have done much better if there had been a certain amount of compulsion available in the background. On this point I fear I may not offer any views here.

\section{REFERENCES}

BLAdini, L. (I925) : "Lex veneris och smittokällorna” ["Lex veneris" and sources of infection], Svenska Läkartidningen, Stockholm.

BLADINI, L. (I93I) : “ Vad kan göras för att motverka den stigande frekvensen av konssjukfomarna?" [What can be done to combat the increasing incidence of venereal disease ?], Ibid.

Kissmeyer, A. (I938) : "The Combating of Veneral Diseases in Denmark." Copenhagen. Bagges Kgl. Hofbogtrykkeri. 


\section{ANTI-VENEREAL MEASURES IN DENMARK}

Lomнolт, S. (I935) : “ Rïckgang der Syphilis in Dänemark, I9I9I933" [Decline of Syphilis in Denmark, I9I9-1933], Dermat. Wschr., 100,173 .

Ministry of Health (1938) : “ Report on Anti-Venereal Measures in Certain Scandinavian Countries and Holland." H.M. Stationery Office. 